\title{
An expanded critical incident approach for exploring information use and learning
}

Hilary Hughes

\begin{abstract}
Critical incidents offer a focus for exploratory research about human experiences, including information use and information literacy learning. This paper describes how critical incidents underpinned research about international students' use of online information resources at two Australian universities. It outlines the development and application of an expanded critical incident approach (ECIA), explaining how ECIA built upon critical incident technique (CIT) and incorporated information literacy theory. It discusses points of expansion (differences) between CIT and ECIA. While CIT initially proved useful in structuring the research, the pilot study revealed methodological limitations. ECIA allowed more nuanced data analysis and the integration of reflection. The study produced a multifaceted word picture of international students' experience of using online information resources to learn, and a set of critical findings about their information literacy learning needs. ECIA offers a fresh approach for researching information use, information experience, evidence-based practice, information literacy and informed learning.
\end{abstract}

\section{Introduction}

Critical incidents offer a compelling focus for exploratory research about human experiences. This paper presents the development of an expanded critical incident approach (ECIA) for a study that explored the experiences of 25 international students using online information resources to learn at two Australian universities. First the paper presents a brief overview of the study's background, its conceptual information literacy frame and its outcomes. After explaining the study's methodological expansion from critical incident technique (CIT) (Flanagan, 1954) to ECIA, the paper introduces the main features of ECIA, highlighting its points of expansion (or differences) from CIT. Next it demonstrates the practical application of ECIA to the study, by outlining its five phases of Planning, Collection, Analysis, Interpretation and Reflection. Finally, it outlines key

\section{Author}

Dr Hilary Hughes is Senior Lecturer and Program Leader of Children and Youth Research Centre, Faculty of Education, Queensland University of Technology, Australia. Her research includes informed learning in culturally diverse contexts.

Email: h.hughes@qut.edu.au 
findings and discusses the potential of ECIA for other research. In this way, the paper updates an account of ECIA at an earlier stage of development (Hughes, 2007) and models a fresh approach for qualitative research in Library and Information Science and associated Education fields, especially information use, information experience, evidence-based practice, information literacy and informed learning.

\section{Overview of the study}

The aim of the study (Hughes, 2009) was to investigate how international students use online information resources to learn, and to identify associated information literacy learning needs. This research arose from the author's professional concerns as academic librarian / information literacy educator. It sought to enhance understanding about the information literacy needs of learners as part of their wider experience of learning in culturally diverse online-intensive environments. Thus, it aimed to counter a tendency in information literacy research and practice to focus on international students' difficulties (for examples see Trew (2006)) and deficit model teaching (Biggs \& Tang, 2007), whilst ignoring the richly varied knowledge and experiences that international students bring to study in their host country

Significantly, the study addressed imperatives of educational equity and sustainability, highlighting the need to respond to international students as both information using learners and educational consumers. In Australia, international students constitute a significant proportion (about 18\%) of the student population and they contribute substantially to the national economy and to the sustainability of many universities (Australian Bureau of Statistics, 2007; Bourke \& LucadouWells, 2010; Kevat and Shroff, 2010; Marginson, 2006). Accordingly:

The relationships formed through international education underpin Australia's engagement with the world, and help sustain goodwill, trade and investment ... Trade in education contributes to revenue growth for education providers, thereby strengthening the financial viability of institutions and increasing opportunities for participation in education, research and employment.

(Group of Eight Australia, n.d.)

From the theoretical perspective, the research aligned with information literacy and the search for understanding about the different ways people experience using information (Bruce, 1997). It was framed by two key concepts: that information literacy is 'a complex of different ways of interacting with information' (Bruce, Edwards and Lupton, 2006, 18); and that there is an inextricable connection between using information and learning (Bruce 2008; Lupton 2008) In this research context, learning is understood as 'coming to experience the world in new ways' (Bruce, 2008, 5) when learners develop understanding or knowledge about something by experiencing it in qualitatively different ways (Marton and Booth, 1997). Therefore, the study viewed international students as information using learners, and the use of online information resources as integral to the whole learning experience rather than discrete digital skills. 
From the methodological perspective, the exploratory purpose of the research called for a qualitative approach that would yield rich insights drawn from reallife experiences. As detailed later in this paper, this purpose was achieved by collecting and analysing critical incidents associated with students' use of online resources for particular assignments.

\section{From CIT to ECIA}

This qualitative study (Denzin and Lincoln, 2005; Patton, 1990) evolved in a quilt-like, emergent manner (Lincoln and Guba, 1985). After starting as a relatively small-scale investigation of international students' difficulties in using online information resources, the study evolved into a more complex exploration of their whole experience of using online information resources to learn. Conceptually, the research focus widened from resources and information skills, to using information and learning (Bruce, 2008; Lupton, 2008).

The widening focus prompted a methodological shift from critical incident technique (CIT) to expanded critical incident approach. Initially the author chose CIT as research method, since it seemed to offer a straightforward method to gather and analyse qualitative data about successful/unsuccessful use of online information resources. However, as the research focus widened from activity to experience, it needed a method that would accommodate more complex and nuanced data. After examining various alternative methods, the decision was taken to expand (rather than abandon) CIT. Thus, in order to appreciate ECIA, it is necessary to first consider the CIT base that it builds on.

\subsection{Critical incident technique}

CIT was developed in the nineteen forties by John Flanagan (1954), an American researcher in the field of occupational psychology. Flanagan devised CIT to identify effective (and ineffective) behaviours relating to a particular activity. Initially CIT was used by the US military during World War II for the selection, performance appraisal and training of pilots. Over the following three decades Flanagan and associates extended the scope of CIT to the fields of personnel management, health and community services and education.

CIT is a practical investigative tool, rather than a theoretically based method. It involves five steps: establish general aims; establish plans and specifications; collect the data; analyse the data; interpret and report the data. It offers:

A set of procedures for collecting direct observations of human behavior in such a way as to facilitate their potential usefulness in solving practical problems and developing broad psychological principles. The critical incident technique outlines procedures for collecting observed incidents having special significance and meeting systematically defined criteria.

(Flanagan, 1954, 327)

CIT draws on people's first-hand accounts to build a picture of human activity in real-life settings. It "encourages participants to tell their story" (Urquhart, Light, Thomas, Barker, Yeoman, Cooper, Armstrong, Fenton, Lonsdale \& Spink, 2003), by recalling critical incidents, or significant instances of a particular activity, 
which they have either carried out themselves or observed someone else carrying out. Participants are asked to describe particular aspects (generally positive and negative) of the incident. Thus:

An incident is critical if it makes a 'significant' contribution, either positively or negatively to the general aim of the activity' and it should be capable of being critiqued or analysed.

(Flanagan, 1954, 338)

Flanagan emphasised that critical incidents represented only raw data and did not automatically provide solutions to problems. CIT findings were intended to provide a basis for performance evaluation, program development, problemsolving, theory building and further research. Stressing the "scientific" validity of CIT and its relatively high levels of objectivity, Flanagan stated:

The critical incident technique, rather than collecting opinions, hunches and estimates, obtains a record of specific behaviors from those in the best position to make the necessary observations and evaluations.

(Flanagan, 1954, 355)

CIT's original purpose, as a scientific tool for objective investigation of human behaviour, reflected the prevailing positivist paradigm (Chell, 1998). However, CIT has come to be used primarily as a tool for qualitative investigation that takes place in a natural setting; the researcher assumes the role of research instrument by posing questions and interpreting responses as a means to understanding a reallife phenomenon or aspect of human experience (Butterfield, Borgen, Amundson \& Maglio, 2005; Kain, 2004).

\subsection{Advantages of CIT}

Initially, CIT seemed a suitable method for this study (Hughes, 2009) for four reasons. First, CIT's emphasis on real-life activity coincided with the exploratory research aim. Previous studies (e.g. Ellinger \& Watkins, 1998; Kain, 1997;

Radford, 2006) had shown that CIT lends itself to qualitative investigation, with critical incidents providing authentic focus and prompting participant recall. It can promote understanding of a phenomenon (Woolsey, 1986) and yield rich, contextualized data that illuminate lived and shared reality (Kain, 2004).

Second, as Christie and Young $(1995$, p.7) point out, CIT is "grounded ... in common sense procedures". Thus it offered a practical approach to data collection and analysis, with clearly defined guidelines for planning and implementing the study. Moreover, CIT is able to manage the large amounts of qualitative data, and to assist the identification of broad patterns and understandings (Chell,1998).

Third, CIT had a well proven record as an exploratory and investigative tool (Butterfield, Borgen, Maglio \& Amundson, 2009; Chell 1998; Ellinger \& Watkins, 1998). Researchers had demonstrated its reliability and validity (Ronan and Latham, 1974). More recently Butterfield, Borgen, Amundson \& Maglio (2009) developed and implemented a set of credibility checks which further strengthen CIT's trustworthiness for qualitative research. CIT continues to be used widely across the social sciences, including the disciplines of this study: 
Information Science (e.g. Armstrong, Everitt, Fenton, Lonsdale, McDermott, Phillips, Spink, Thomas \& Urquhart, 2001; Radford, 2006; Tenopir, King, Edwards, \& Wu, 2009) and Education (e.g. Kain, 1997; LeMare \& Sohbat, 2002; Voss, Gruber \& Reppel, 2010)

Fourth, critical incidents had been shown to provide useful stimuli for learning and reflection (Chell, 1998; Christie \& Young, 1995; Tripp, 1993). This aligned with the study's intention to provide an evidence base for enhancing information literacy education.

\subsection{Limitations of CIT}

Early data collection and analysis for this study (Hughes, 2009) proved quite fruitful. Having defined critical incidents as instances of using an online resource for an assignment, the author conducted pilot study interviews where participants were asked to: "Tell me about a time when you found it easy/hard to use online resources for an assignment. Please explain why you found it easy/hard". The students provided plentiful incidents and CIT binary analysis enabled the identification of various difficulties - and strengths - experienced by international students in using resources.

Gradually, the author became aware of a number of limitations in both the scope and method of the study. On a methodological level, the semi-structured interviews were producing a wealth of data that were not accommodated by CIT's tight binary categorisation. While CIT proved effective for investigating the students' information use behaviours, it could not encompass the nuanced qualitative dimensions of their information using experience, as evident in their affective and reflective responses and cultural and linguistic influences. As a result, the author became concerned that the findings might promote the stereotypical understandings about international students and the deficit model, skills-oriented information literacy teaching which she sought to counter. A further problem was that whereas CIT Steps 1-4 are highly prescriptive about data collection and analysis, Step 5 offers minimal guidance for interpreting and reporting the findings.

On a conceptual level, the author regretted CIT's lack of theoretical underpinning, unlike grounded theory (Glaser, 1998) or phenomenography (Marton and Booth 1997), which are commonly used methods in information literacy research. CIT specifies practical procedures, without considering the whole context and scope of the investigation. For example, Step 1 requires the researcher to define the activity under investigation and the aim of the activity, without reference to the overall aim of the research. Moreover, CIT forced a narrow focus on information use as a behaviour or skill, which conflicted with the holistic understanding of information literacy as "using information to learn" (Bruce, 1997; 2008) which underpinned the study.

\subsection{Extending the research scope}

Following the initial phase of data collection, the author determined to extend the research scope beyond identifying international students' difficulties in using online resources, to exploring their whole experience of using online information 
to learn, a concept that aligned with the emerging concept of informed learning (Bruce, 2008; Lupton, 2009). This led the author to explore alternative qualitative methods including grounded theory (Glaser, 1998), phenomenography (Marton and Booth 1997) and action research (Zuber-Skerritt, 1996). While each had its merits, none was entirely appropriate for this study, without a major overhaul or fresh start. For example, action research required a higher level of participation than the research timeframe or circumstances allowed, and the literature review and theoretical framing was already too far advanced for the clean slate approach of grounded theory.

After considerable deliberation, the author decided to explore where CIT, in a modified form, could take this research. She was guided by Flanagan's view of CIT as a "flexible set of principles which must be modified and adapted to meet the specific situation at hand" (Flanagan, 1954, p. 335) and the fact that CIT had proved hospitable to changing research environments and researchers had successfully modified the method in various ways (Ellinger \& Watkins, 1998; FitzGerald, Seale, Kerins \& McElvaney, 2008). In widening CIT's application from purely behavioural concerns to wider aspects of human experience, researchers had modified it to define characteristics and contributing factors of successful or unsuccessful outcomes of an activity and to examine the reasons and significance people attach to particular activities (Chell, 1998; Kain, 2004). Moreover, some researchers had found useful compatibilities between CIT and other research methods, such as case study (MacIntosh-Murrray, 2003), explicitation (Urquhart, Light, Thomas, Barker, Yeoman, Cooper, Armstrong, Fenton, Lonsdale \& Spink, 2003) and grounded theory (Chell, 1998). Thus, in developing ECIA, the author was encouraged that:

The CIT has proven to be a versatile, adaptive ad robust research method that will likely continue to evolve as researchers utilize it to shed light on new and innovative research questions.

(Butterfield, Borgen, Maglio \& Amundson, 2009, 278-9)

\section{Introducing expanded critical incident approach}

Rather than being a revised version of critical incident technique (Flanagan, 1954), the expanded critical incident approach is a related approach with a distinctive nature and purpose that builds upon CIT. Whereas CIT is an effective technique for data collection and analysis, ECIA encompasses the whole research process within a conceptual frame. Whereas CIT involves a systematic procedure though five steps, ECIA supports an iterative process between five inter-related phases: Planning, Collection, Analysis, Interpretation and Reflection. As the following Table 1 shows, ECIA's five phases align broadly with the five steps of critical incident technique (Flanagan, 1954). However, the ECIA Planning phase incorporates CIT Steps 1 and 2 and there is an additional Reflection phase. 


\begin{tabular}{|c|c|}
\hline $\begin{array}{c}\text { Five Steps } \\
\text { Critical incident technique (CIT) } \\
\text { (Flanagan 1954) }\end{array}$ & $\begin{array}{c}\text { Five Phases } \\
\text { Expanded critical incident approach } \\
(\text { ECIA })\end{array}$ \\
\hline $\begin{array}{l}\text { Step 1: Establish the general aims } \\
\text { - Define the activity to be studied and } \\
\text { establishes the aim of the activity }\end{array}$ & \multirow{2}{*}{\begin{tabular}{ll} 
& \multicolumn{1}{c}{ Planning } \\
- & Identify the activity to be explored \\
- & Elaborate the research aim \\
- & Conelop the conceptual frame \\
- & Identify nature of critical incidents \\
- & Plan data collection and analysis \\
& strategy \\
\end{tabular}} \\
\hline $\begin{array}{l}\text { Step 2: Establish plans and } \\
\text { specifications } \\
\text { - Develop a detailed and defensible } \\
\quad \text { plan of attack for data collection. }\end{array}$ & \\
\hline $\begin{array}{l}\text { Step 3: Collect the data } \\
\text { - Collect data in the form of critical } \\
\text { incidents for the activity }\end{array}$ & $\begin{array}{l}\text { Collection } \\
\text { - Collect data associated with the } \\
\text { activity being explored } \\
\text { - Focus on critical incidents and } \\
\text { participants' environment, attributes, } \\
\text { actions and responses }\end{array}$ \\
\hline $\begin{array}{l}\text { Step 4: Analyze the data } \\
\text { - Inductive data analysis process for } \\
\text { classifying critical incidents, } \\
\text { generally on a binary } \\
\text { (positive/negative) basis. } \\
\text { - Establish a frame of reference (main } \\
\text { categories) and arrange critical } \\
\text { incidents in mutually exclusive } \\
\text { categories and sub-categories, of } \\
\text { decreasing generalisability and } \\
\text { increasing specificity. } \\
\text { - Compile a set of critical behaviours. }\end{array}$ & $\begin{array}{l}\text { Analysis } \\
\text { - Undertake inductive data analysis } \\
\text { process involving binary and thematic } \\
\text { categorisation } \\
\text { - } \text { Create thematic representation of } \\
\text { participants' whole experience } \\
\text { - Compile a set of critical findings }\end{array}$ \\
\hline \multirow[t]{2}{*}{$\begin{array}{l}\text { Step 5: Interpret and report the data } \\
\text { - Interpret and report the data in line } \\
\text { with intended application of the } \\
\text { findings. }\end{array}$} & $\begin{array}{l}\text { Interpretation } \\
\text { - Identify the various elements of the } \\
\text { participant's experience and } \\
\text { inter-relationships between elements } \\
\text { - Identify the implications of the } \\
\text { findings for the participants and } \\
\text { others }\end{array}$ \\
\hline & $\begin{array}{l}\text { - Reflection } \\
\text { - Reflect continuously through all } \\
\text { phases, to support planning and } \\
\text { implementation of the study, and } \\
\text { interpretation of the findings } \\
\text { - } \quad \text { Reflect backwards to identify } \\
\text { strengths and limitations of the } \\
\text { research } \\
\text { - Reflect forwards to support } \\
\text { application of the findings and } \\
\text { identify further research needs }\end{array}$ \\
\hline
\end{tabular}

\section{Table 1 Comparison of CIT's five steps and ECIA's five phases}

CIT and ECIA share a common concern with human experiences associated with a particular activity, which are explored through the collection, analysis and 
interpretation of data relating to critical incidents. However, there are five notable differences - or points of expansion - between CIT and ECIA as outlined below.

First, while CIT is a practical tool for data collection and analysis, ECIA became the whole conceptual and methodological framework for the present study. While CIT's five steps concentrate on procedures for data collection, analysis and interpretation within a study, the five phases of ECIA encompassed the design and implementation of the whole study. For example, CIT Step 1 requires the researcher to define the activity under investigation and the aim of the activity; whereas, in the ECIA Planning phase, the aim of the whole research project and its overarching concept were defined. Moreover, Reflection (Moon, 2004; Schön, 1987) was added as an additional phase to guide all aspects of the research.

Second, CIT steps are sequential while ECIA phases are inter-connected and unnumbered. In Figure 1 below, the points of the star represent the five phases of the expanded critical incident approach. The straight lines around and across the star show multiple connections across all five phases, in all possible directions. They represent a continuous, iterative progression back and forth, as data emerge, new understandings develop and further research needs become apparent.

Planning and Reflection, which support all phases of ECIA, play similar roles in ECIA as in action research (Zuber-Skerritt, 1996).

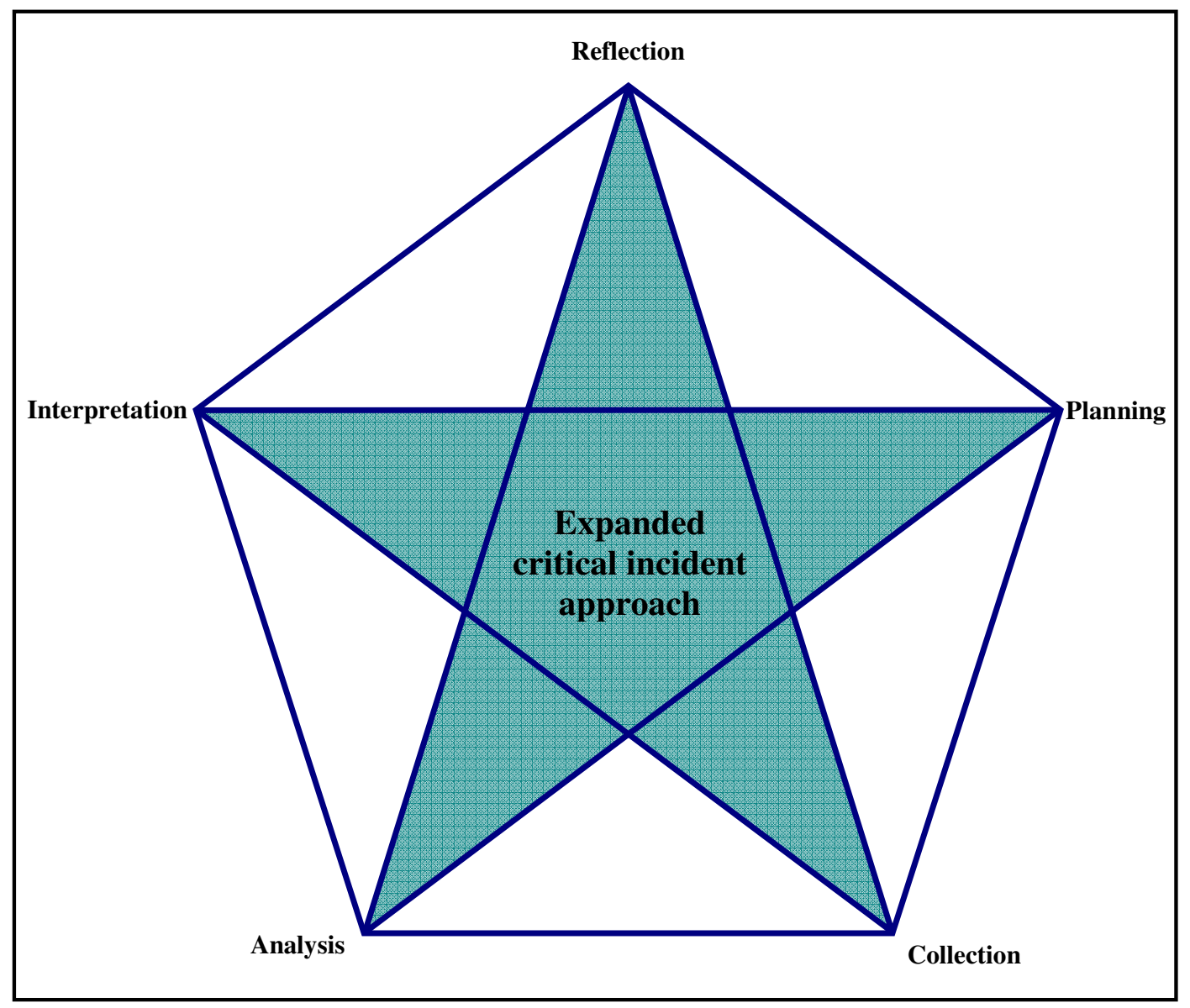

Figure 1: Five phases of expanded critical incident approach 
Third, ECIA shifted emphasis from participants' behaviours to human experiences. Originally, in line with CIT, the study concentrated on what resources the international students used and how they used them. In contrast, the revised (ECIA) study considered the students' whole information-using experience, by examining their interactions with online resources, as well as their learning context, affective and reflective responses to using online resources, and cultural-linguistic dimensions.

Fourth, CIT data collection generally involves a large sample population and gains hundreds of critical incidents relating to a narrowly defined activity; and data collection ceases when data analysis indicates redundancy. However, since this study sought individuals' insights from their whole experience of using online information resources to learn, ECIA involved a relatively small purposefully selected participant group, as is common in qualitative research (Denzin \& Lincoln, 2005; Patton, 1990); there was no expectation of achieving redundancy, since the findings were intended to be indicative rather than generalisable, to provide insights about individual students' experiences in a particular educational context.

Fifth, CIT data analysis is limited to binary (positive/negative) categorisation, while ECIA involved binary and thematic categorisation. CIT findings are generally limited to sets of critical behaviours, while this study created a nuanced overview of international students' experience of using online resources, in addition to a set of critical findings about their information literacy learning needs.

The following section outlines ECIA as applied in this study. It offers a guide to other researchers seeking a qualitative method that explores people's experiences of a particular activity in a real-life context.

\section{Applying ECIA to the study}

Applying ECIA to the study involved a continuous process of development, implementation, review and revision, moving around and through the five ECIA phases, shown in Figure 1 (above). Each phase is now outlined below.

\subsection{Planning Phase}

Planning was a constant throughout the study, associated with broad-scale research design and particular strategies. Initially, Planning involved establishing a research framework that integrated both conceptual and methodological principles. The study's overarching concept was defined as: using online information resources to learn is a complex experience. This concept aligned the study with Bruce's (1997) relational model of information literacy and the notion of an inextricable connection between using information and learning (Bruce, 2008; Lupton, 2008). It reflected an understanding of information literacy as "a complex of different ways of interacting with information" (Bruce, Edwards \& Lupton, 2006, 18).

CIT's first step requires the researcher to identify the activity being studied and the aim of the activity. However, according to ECIA, the study's research aim was first defined as being: 
To investigate how international students use online information resources to learn, and to identify associated information literacy learning needs.

Next the activity being studied was identified as:

Using online information resources.

Then following Flanagan (1954), the aim of the activity, was defined through consultation with experts. Given the information literacy orientation of the research, the experts were academic librarians from four Australian universities and five LIS research colleagues. They responded to the question:

What do you consider to be the aim of using online information resources?

Integrating key elements of their responses, the following statement was compiled:

The aim of using online information resources is to gather information, develop understanding, widen experience, overcome challenges, adopt critical perspectives, construct knowledge, create new meanings and achieve learning outcomes.

Synthesising the experts' responses, it was determined that:

The aim of using online information resources is to learn.

The above statement acted as a touchstone for the study's subsequent planning and implementation.

In preparation for data collection, the author developed a participant recruitment plan. Considering the exploratory nature of this study, she determined that the participant group needed to be of a size and composition that would: allow a sole researcher to effectively conduct in-depth interviews with individual participants, yet reflect the diversity of international students in Australia. The optimum participant group would include 20 to 30 international students of varied nationalities and language backgrounds, with a spread of age and gender, and a balance of undergraduates and postgraduates. The participants should be enrolled in an Information Technology or Business degree course at an Australian university with high international student enrolment and within their first 18 months of study in Australia.

For this study critical incidents were designated as recent instances of using online resources for an assignment. Each participant would contribute two critical incidents: one relating to an actual course-related assignment that the student had carried out; one relating to a simulated assignment that the researcher would observe the student carrying out.

In the researcher's estimation, assignments constituted valid critical incidents for four reasons:

- in undertaking assignments, the students engaged in the specified activity of using online information resources

- assignments generally represent significant events in students' lives

- assignments constitute part of the learning process and so are associated with the concept of using information to learn 
- $\quad$ since students regularly undertake assignments, the participants would be able to provide recent, first-hand accounts of the activity.

\subsection{Collection Phase}

The Collection phase involved recruiting participants and gathering critical incident data relevant to the activity of using online information resources. Since Flanagan (1954) offers limited advice on how to conduct CIT interviews, in this phase the researcher drew on qualitative research authorities including Flick (2002), Kvale (1996) and Patton (1990).

In recruiting participants, a purposeful, self-selecting approach was adopted (Patton 1990). To invite participation, several hundred international students were provided information by means of notice boards, visits to Business and IT classes and follow-up emails. The participant group of 25 undergraduates and postgraduate international students from two Australian universities achieved the recruitment criteria. The group reflected the diversity of the international student population in Australia (Australian Bureau of Statistics, 2007; Kevat and Shroff, 2010) with individuals from fifteen different countries across Asia, Europe (including UK), the Middle East, India and South America. Collectively they spoke about 20 different languages, with English their common but not usually their first language.

Data collection involved semi-structured interviews, to elicit both factual information and participants' perceptions (Flick, 2002; Patton, 1990). The interviews were designed to address the what? how? why? of the students' resource-using experiences (Kvale, 1996). Thus, as shown in Table 2 below, the interviews included some questions with a CIT-influenced positive/negative nature, while others allowed more expansive responses in line with ECIA.

Before the start of each interview, the researcher gave participants an information sheet explaining the scope and purpose of the study and conditions of their participation. In accordance with university research ethics requirements, each participant was asked to complete a form indicating their informed consent. To acknowledge their contribution to the research, each student was offered free tuition in using online information resources after their interview.

The semi-structured interviews generally lasted between 60 and 90 minutes and were in four parts: informal opening conversations; completion of online resource checklist; open-ended questions; and observed online task. These complementary data collection strategies achieved triangulation (Flick, 2002) between the students' first-hand accounts of how they had used resources on a previous occasion, and my observations of them actually using resources. It also eased communication by enabling the participants to both describe and demonstrate their online resource use. 


\begin{tabular}{|c|c|}
\hline Question & $\begin{array}{l}\text { Nature of the } \\
\text { question: }\end{array}$ \\
\hline $\begin{array}{l}\text { What types of information did you need? (Tick checklist - } \\
\text { yes/no) }\end{array}$ & CIT \\
\hline $\begin{array}{l}\text { 2) Which online resources did you use? (Tick checklist - } \\
\text { yes/no) }\end{array}$ & CIT \\
\hline $\begin{array}{l}\text { 3) What did you find easy (or hard) about using online } \\
\text { resources? Why? }\end{array}$ & CIT + ECIA \\
\hline $\begin{array}{l}\text { 4) What help did you gain help in using online resources for } \\
\text { this assignment? }\end{array}$ & CIT + ECIA \\
\hline 5) How did you gain help to use online resources? & ECIA \\
\hline $\begin{array}{l}\text { 6) Overall, would you say that using online resources for this } \\
\text { assignment was a positive experience/was not a positive } \\
\text { experience? Why? }\end{array}$ & CIT + ECIA \\
\hline $\begin{array}{l}\text { 7) In what ways did being an international student affect your } \\
\text { use of online resources? }\end{array}$ & ECIA \\
\hline $\begin{array}{l}\text { 8) What do you think could be done to make online } \\
\text { information searching a more positive experience for } \\
\text { international students? }\end{array}$ & ECA \\
\hline $\begin{array}{l}\text { 9) How would you sum up your thoughts and feelings about } \\
\text { using online information resources? }\end{array}$ & ECIA \\
\hline
\end{tabular}

\section{Table 2: Interview questions}

In conducting the interviews, the researcher was mindful of the international students' cultural and linguistic diversity. Throughout, she took care to explain the interview processes and speak clearly, reiterating or rephrasing questions where necessary. First, aiming to create a relaxed interview environment, the researcher invited the participants to talk about their home country and the languages they spoke; their previous educational and professional experiences; their transition to life and study in Australia; and their previous use of online information resources.

Second, having broken the ice, the focus moved onto a specific critical incident by inviting the participants to:

Think about an assignment that you have done at your Australian University that required you to search for information using online information resources.

The participants were asked to describe the assignment topic and requirements, and to indicate on a checklist which online resources they had used. The checklist aimed to overcome uncertainties with specialist terminology and difficulties in recalling the names of particular online resources, which had been noticed during pilot interviews. This part of the interview relates to questions 1 and 2 in Table 2 above.

The third part of the interview centred around a series of open-ended questions, with follow-up probes to clarify meanings or gain further information. The main questions are numbered 3-9 in Table 2 above. 
Finally, each participant was observed using online resources for an online task. This sought data about the students' resource using practices, such as planning and implementing a search strategy, selecting keywords and evaluating results. The task simulated an assignment on the topic:

Prepare an annotated bibliography on effective public speaking techniques for business.

The students were asked to demonstrate how they would search for and select information on this topic, using the library catalogue, a journal database and an Internet search engine. They were encouraged to describe their thoughts and actions whilst carrying out the task. The online task was designed to be authentic and straight forward to carry out, whilst capable of yielding plentiful data. The topic was sufficiently generic to be meaningful to students across disciplines. Its wording and requirements reflected real university assignments and included points of potential challenge. It was determined that an effective search strategy would: focus on the two-part phrase public speaking for business; combine the terms business and "public speaking"; and exclude non-essential words effective, techniques and annotated bibliography. The latter was also included to assess whether the participants were familiar with this academic terminology.

In all, the interview questions and observed task gained data relating to 48 assignments ( 25 real and 23 simulated) that had involved the use of online resources. The richly varied data covered students' resource-using actions, as well as affective and reflective responses and cultural-linguistic influences.

\subsection{Analysis Phase}

Analysis, which occurred concurrently with data collection, sought to uncover aspects of the participants' resource-using experiences, and to identify particular information literacy learning needs. It involved an inductive process (Ezzy, 2002; Patton, 1990), whereby patterns were sought among the wide range of data drawn from students' narrative and resources checklists, and the researcher's observations. In a manner similar to grounded theory (Glaser, 1998) the researcher examined, coded and re-examined interview transcripts, sifting and sorting data, developing and revising categories as new data emerged and relationships became apparent. To accommodate the varying data types two different categorisation strategies were applied: binary and thematic. Binary categorisation is typical of CIT (Flanagan, 1954). It was used to identify factual details, for example: particular online resources that the students used or did not use; and particular aspects that they found easy or hard. Thematic analysis (Ezzy, 2002; Patton, 1990) allowed more nuanced analysis than binary categorisation and captured qualitative aspects, such as students' affective responses to online resources, or cultural-linguistic dimensions of particular resource using challenges. Gradually, a framework of inter-related categories was created. In contrast to CIT's mutually exclusive categories, this framework allowed for relationships in the data, across and within categories. In the course of the study, the category framework was revised several times, which demonstrates the flexibility of ECIA for qualitative analysis. Thus the final framework (Hughes, 2009) differs substantially from the previously published version (Hughes, 2007). 
The analysis process identified eight main categories, which represent the following key elements of the students' experience of using online information resources to learn:

- Students: attributes and background of the international student participants

- Information-learning environment: nature of the Australian university and online environment in which the students were using online resources

- Interactions: the students' use / non-use of particular online information resources and their approaches to using them

- Strengths-Challenges: points of strength and difficulty experienced by the students in using online information resources

- Information-learning: the students' participation/non-participation in formal information literacy education, and informal help seeking for using online resources

- Responses: the students' affective responses (more positive/less positive) to using online resources

- Reflections: the international students' reflective responses on the whole experience of using online information resources to learn; involves backwards reflection (more positive/less positive aspects of their experience) and forwards reflection (suggestions for improving international students' experience of using online resources)

- Languages-Cultures: cultural-linguistic dimensions of the students' resource using experiences

The eight elements were inter-connected, yet each had a distinctive flavour. Thus, for example, a particular Interaction with online resources was often associated with a range of other Interactions, as well as other dimensions such as Responses and Languages-Cultures. Most of the main categories (Elements) contained more specific sets and sub-sets of data. For example, as shown in Table 3 below, the Interactions element has two sets, Resources and Approaches, which respectively relate to what resources students used (or did not use) for a recent assignment and how they used them during the observed online task. The right hand column indicates the differing binary and thematic strategies used in analysing these data. For the Resources set shown below, particular resources were grouped in sub-sets, by type of resource (e.g. journal database), then by name of resource (e.g. ProQuest). Then, applying binary categorisation, resources were coded as $\mathrm{U}$ (used) or NU (not used) according to students' checklist responses. For example, the following annotation indicates that a student used a journal database, specifically ProQuest (but not Emerald):

- Journal database (U)

- ProQuest (U)

- Emerald (NU)

Data in the Approaches set underwent a three-part analysis of how the students used online resources for the observed online task. First, each student's Interactions with online resources were evaluated, using criteria devised for this purpose. The criteria related to the four phases of the Reflective online information use model (Hughes, Bruce \& Edwards, 2007). Second, Interactions data were allocated to four sub-sets associated with the main components of the 
model: plan, act, record and reflect. These data related to both macro level Interactions, such as developing an information search strategy [Plan], or micro level Interactions, such as accessing a database [Act] or evaluating a particular journal article [Reflect]. By applying binary categorisation, each Interaction was coded as S or US (successful or unsuccessful), for example:

- Plan - Select search terms (S)

- Reflect - Evaluate journal article (US)

Third, the comments students made whilst carrying out the online task were thematically analysed. The comments complemented the evaluation results by providing insight into students' thoughts and feelings and particular strengths or challenges whilst using the online resources. In some cases they also explained students' particular choices or actions during the task.

\begin{tabular}{|c|c|c|c|}
\hline $\begin{array}{c}\text { Element \& } \\
\text { Definition }\end{array}$ & Sets & Sub-sets & $\begin{array}{l}\text { Analytical } \\
\text { strategy }\end{array}$ \\
\hline \multirow[t]{2}{*}{$\begin{array}{l}\text { Interactions } \\
=\text { Students' } \\
\text { engagement with } \\
\text { online resources }\end{array}$} & $\begin{array}{l}\text { Resources } \\
=\text { What online } \\
\text { resources the } \\
\text { participants used } \\
\text { for an assignment }\end{array}$ & $\begin{array}{l}\text { Journal databases } \\
\text { - ProQuest } \\
\text { - Emerald (etc) } \\
\text { Specialist info } \\
\text { sources } \\
\text { - CCH } \\
\text { - ABS (etc) } \\
\text { Search engines } \\
\text { - Google } \\
\text { - Yahoo (etc) } \\
\text { Library catalogue }\end{array}$ & $\begin{array}{l}\text { Binary } \\
\text { categorisation: } \\
\text { - Used (U) } \\
\text { - Not Used (NU) }\end{array}$ \\
\hline & $\begin{array}{l}\text { Approaches } \\
=\text { How the } \\
\text { participants used } \\
\text { online resources } \\
\text { during the online } \\
\text { task }\end{array}$ & $\begin{array}{l}\text { Plan } \\
\text { - Develop search } \\
\text { strategy (etc) } \\
\text { Act } \\
\text { - Enter search } \\
\text { terms (etc) } \\
\text { Record } \\
\text { - Save search } \\
\text { results (etc) } \\
\text { Reflect } \\
\text { - Evaluate search } \\
\text { results (etc) }\end{array}$ & $\begin{array}{l}\text { Binary } \\
\text { categorisation } \\
\text { - Successful (S) } \\
\text { - Unsuccessful } \\
\text { (US) } \\
\underline{\text { and }} \\
\text { Thematic } \\
\text { categorisation }\end{array}$ \\
\hline
\end{tabular}

Table 3 Extract of Analytical framework

In addition to the categories and sets described above, six themes or critical features were identified which recurred across all elements and describe distinctive qualities of the international students' whole experience. They are as follows: 
- Diversity: e.g. of international students' cultural and educational backgrounds, resources used

- Unfamiliarity: e.g. with online resources, academic terminology, cultural references

- Overflow: e.g. of information resources, research results

- Limited support: e.g.in help-seeking, information literacy learning opportunities

- Shared experience: e.g. undergraduates / postgraduates, online-intensive learning environment

- Imbalance: e.g. between students' well developed digital skills and less developed critical and strategic approaches to using online information

\subsection{Interpretation Phase}

The Interpretation phase both flowed from and informed the Collection and Analysis phases, demonstrating the iterative nature of ECIA. The focus of this phase was to address the research aim, to seek and convey understandings about international students' information using experiences and learning needs. It involved critical engagement with the data in compiling the study's findings, identifying and discussing their implications, and formulating recommendations.

Given the information literacy orientation of the study, the 'consumers' of the research (Kain, 2004, 77) were considered to be primarily educators and information professionals. Therefore the researcher's guiding question for interpretation was:

What do educators and information professionals need to know about the experiences of international students, in order to support their information literacy learning?

In order to remain focused on the intended application of the findings for information literacy development, the researcher continuously asked herself:

- What does this particular data reveal about the students, or their context, or their learning-related resource use?

- Does it convey fresh information or perspective?

- Does it confirm or counteract other information or perspectives already categorised?

- What does it tell about their information literacy learning needs?

Through Analysis and Interpretation the researcher gradually created a word picture and set of critical findings to represent international students' experience of using online resources and their associated information literacy learning needs. The word picture and critical findings are complementary. The former, which illustrates the complex multifaceted nature of the international students' experience, integrates contextual, personal and factual detail and descriptive narrative, their thoughts and feelings. Student vignettes and direct quotations add to the reality and vitality of the word picture. In its nature and purpose, the word picture reflects Ezzy's analogy of a 'multidimensional tangled ball of wool':

There are many threads that interweave through the complex set of interviews, reflections and observations. The task of writing is to reconstruct this 
multifaceted, multidimensional ball of information into a linear story with a beginning, middle and end.

(Ezzy, 2002, 138)

The critical findings correspond with, but extend beyond, CIT's critical behaviours. They summarise key aspects of the students' information literacy learning needs and provide an evidence-base for developing curriculum and pedagogy that respond to these needs.

\subsection{Reflection Phase}

Whilst absent from CIT, reflection was integral to all phases of the ECIA study and supported the planning, implementation, evaluation and reporting of the research. Reflection was particularly important during the Interpretation phase, due CIT's limited guidance for carrying out Step 5. It also brought an evaluative edge to data collection and analysis. For example, the researcher gained a fresh perspective for the categorisation process by analysing each interview question:

What is the essence of this question? What data am I looking for?

She then paraphrased each interview question in the simplest form possible, beginning with an interrogative (What? How? Who?). Changing from second to third person shifted the analytical focus from the students' responses, to the data that the responses contained. In this way a set of analytical focus questions were developed, which allowed a clearer view of what to look for in the participant's responses. For example, one interview question asked:

What do you think could be done to make using online information resources a more positive experience for international students?

When paraphrasing the question, the researcher recognised that it contained three significant elements. Consequently she divided the question into the three following focus questions:

- What information literacy learning needs do the students identify?

- What improvements do they suggest for online resources?

- What improvements do they suggest for information literacy education?

Throughout the study the researcher adopted a self-reflexive approach, drawing on personal critical incidents and critical realisations to review and advance the research. This self-reflexive approach contributed to the trustworthiness of the study's findings (Lincoln \& Guba, 1985). The following final example, relating to data analysis, illustrates the impact of reflection on the researcher's practice and the study's outcomes.

At an early stage of the research, the researcher struggled to find an effective means of evaluating the participants' use of online resources, as observed during the online task. CIT suggested that particular aspects should be assessed as effective or ineffective, but the researcher was uncertain about how or what to assess whilst keeping sight of the whole picture. In reflecting on this challenge, she scanned various journal articles and theses for inspiration. As a critical incident, she chanced across the Action research model for reflective Internet searching (Edwards \& Bruce, 2002) which led her to view the activity of using 
online resources as an action research-type cycle with four inter-related phases: plan-act-record- reflect (Hughes, Bruce \& Edwards, 2007). This critical realisation not only supported the evaluation of the students Interactions during the online task (Section 5.3), but also led the researcher to think of ECIA as a whole approach with five inter-related phases (Figure 1).

\section{Summary of findings}

The study's findings (Hughes, 2009; forthcoming) highlight the diversity of international students as (online) information using learners, with significant information using strengths and challenges. The resultant word picture reflects the complexity of the international students' information using experience by integrating their interactions with online resources, affective and reflective responses and cultural and linguistic dimensions. It shows that at their host Australian university, the international students were immersed in an onlineintensive information-learning environment. They were characterised by the diversity of their cultural, linguistic and educational backgrounds. As information using learners, they brought an array of strengths related to their varied knowledge bases and cultural contexts.

Most of the international students were experienced Internet users. However, when using online resources for study purposes, they experienced various challenges, associated mainly with unfamiliar aspects of their Australian learning environment. These included: journal databases; prevailing academic language and conventions; discipline-specific and library jargon; and the nuances of Australian culture and social practices. The students also tended to experience challenges of 'information overflow' (a term coined by one of the students), associated with the array of academic resources and the abundant information.

The international students experienced a range of affective responses to using online resources, which included frustration and disappointment as well as satisfaction and excitement. They expressed more positive thoughts about using resources, and less positive feelings about the resources themselves, suggesting a more pragmatic acceptance of their usefulness for assignments, rather than any inherent pleasure in using them. Overall, the students appeared to be resilient information-using learners who came to value the contribution online resources made to their assignment work. For example, one student described them as an "asset of education ... a catalyst for you to learn" and another declared them to be "a good friend of mine for doing assignments".

The critical findings detail key information literacy learning needs and highlight an apparent information literacy imbalance (Hughes, Bruce \& Edwards, 2007) between students' often well developed information skills and generally less developed critical and strategic information using approaches. Taken together, the critical findings provide a framework for developing a holistic educational response.

Given the exploratory nature of this study, the findings are descriptive and indicative rather than predictive or generalisable. They might not be representative of international students in general, but they are authentic and contribute understanding about the strengths, challenges and needs an individual may 
present. In particular, they signal a need for information professionals and educators to be aware of, and allow for, possible challenges and emotions of international students who are not completely fluent in English or fully conversant with prevailing academic practices at their host university. They also warn against making generalised assumptions about the nature of international students' challenges. In many respects, such as the information literacy imbalance and information overflow noted above, the international students share common ground with students in the wider student population (Head \& Eisenberg, 2010; Lorenzo \& Dziuban, 2006). Consequently this study concluded by proposing an inclusive informed learning approach (Bruce \& Hughes, 2010) to enhance the information use and learning of all students in culturally diverse higher education contexts.

\section{ECIA potential for other research}

As a part-time doctoral study, this research involved extensive data collection and in-depth analysis over several years. However, the five phase ECIA process, as outlined in Section 5, is relatively straightforward to implement and could be successfully applied to a shorter project or with fewer participants. In addition, ECIA could be used in a variety of professional and academic contexts where understanding about people's real-life needs and experiences is required. For example, in a library / information environment, ECIA findings could contribute an evidence base for developing user-focused policy, planning educational programs or for evaluating client services.

ECIA seeks to expand rather than replace CIT. In all research, the choice of method depends upon a variety of factors which include: the scope and purpose of the investigation; the intended use of the findings; and available resources (time, researchers and funding). While ECIA lends itself to exploratory research that seeks multi-faceted insights about a whole experience (such as library patrons' engagement with digital technologies) CIT is more suited to identifying particular aspects of an activity (such as Google searching). While ECIA provides a holistic, nuanced picture, which includes participants' actions, thoughts, feelings and needs, and cultural-linguistic attributes, CIT focuses on specific aspects such as effective and ineffective searching techniques. ECIA is essentially a qualitative approach, whereas CIT can incorporate qualitative and quantitative analysis. The wide-reaching coverage of ECIA necessitates a relatively small participant group, whereas CIT can accommodate hundreds, or even thousands of participants. In summary, while ECIA and CIT can both address 'how' and 'what' research questions, ECIA can also explain 'why'.

\section{Conclusion}

In outlining recent research about the information using experiences and learning needs of international students, this paper has introduced a fresh approach for exploratory research. The development and implementation of an expanded critical incident approach (ECIA) involved both empirical and methodological exploration, whereby the search for understanding about international students' information use engendered a search for a suitable investigative approach. ECIA's focus on real life critical incidents incorporated the procedural strengths of critical 
incident technique, with more nuanced data analysis and reflective research practice. The potential of this approach is evident in the study's findings, which present a detailed picture of international students' experiences of using online information resources to learn, and also identify significant information literacy learning needs. While the study's findings advance information literacy theory and practice, its expanded critical incident approach would support further qualitative research and methodological development in the fields of information use, information experience, evidence-based practice and informed learning.

\section{References}

Armstrong, C. J., Everitt, J., Fenton, R., Lonsdale, R. E., McDermott, E. A., Phillips, R., Spink, S., Thomas, R. E. and Urquhart, C. J. (2001). JISC usage surveys: Trends in electronic information services. Final report 2000/2001 cycle (Cycle Two ). Aberystwyth: University of Wales Aberystwyth. Department of Information and Library Studies. URL: http://www.dil.aber.ac.uk/dils/research/justeis/cyc2rep.pdf [accessed 18.09.11].

Australian Bureau of Statistics (2007). 4102.0 - Australian Social Trends, 2007: International students in Australia. URL: http://www.abs.gov.au/AUSSTATS/abs@.nsf/Latestproducts/E0FE4ACEF9C8A 65ACA25732C00207596 [accessed 18.09.11].

Biggs, J.B. and Tang, C.S. (2007). Teaching for quality learning at university: What the student does. $3^{\text {rd }}$. ed. Maidenhead : McGraw-Hill/Society for Research into Higher Education \& Open University Press.

Bourke, J.F. and Lucadou-Wells, R. (2010). Towards creating sustainable Australian international education. Macquarie Journal of Business Law [online], 7, 87-97. URL:http://hdl.handle.net/1959.14/110440 [accessed 4.9.11].

Bruce, C. S. (1997). The seven faces of information literacy. Adelaide: Auslib Press.

Bruce, C. S. (2008). Informed learning. Chicago, Il.: ALA Editions.

Bruce, C.S., Edwards, S. and Lupton, M. (2006). Six frames for information literacy education: A conceptual framework for interpreting the relationships between theory and practice. Italics [online], 5(1). URL: http://www.ics.heacademy.ac.uk/italics/vol5-1/pdf/sixframes_final\%20_1_.pdf [accessed 18.09.11].

Bruce, C. S. and Hughes, H. (2010) Informed learning: A pedagogical construct attending simultaneously to information use and learning. Library and Information Science Research, 32(4), A2-A8.

Butterfield, L. D., Borgen, A., Amundson, N. E and Maglio, A-S.T. (2005). Fifty years of the critical incident technique: 1954-2004 and beyond. Qualitative Research, 5(4), 475-497. 
Butterfield, L. D., Borgen, A., Maglio, A-S.T. and Amundson, N. E. (2009). Using the enhanced critical incident technique in counselling psychology research. Canadian Journal of Counselling, 43(4), 265-282.

Chell, E. (1998). Critical incident technique. In G. Symon, \& C. Cassell (Eds.). Qualitative methods and analysis in organizational research (51-72). London: Sage.

Christie, M. F. and Young, R. M. (1995), Critical incidents in vocational teaching: A Northern Territory study. Darwin: Northern Territory University.

Denzin, N. and Lincoln, Y. (2005). Introduction: the discipline and practice of qualitative research. In N. Denzin, \& Y. Lincoln (Eds.), The Sage handbook of qualitative research ( $3^{\text {rd }}$ ed., pp.1-32). London: Sage.

Edwards, S. L. and Bruce, C. S. (2002). Reflective Internet searching: An action research model. The Learning Organization, 9(4), 180-188.

Ellinger, A. D. and Watkins, K.E. (1998). Updating the critical incident technique after forty-four years: advances in qualitative research. In Academy of Human Resource Development Conference Proceedings. (ERIC Document Reproduction Service No. ED 428234).

Ezzy, D. (2002). Qualitative analysis: practice and innovation. London: Routledge.

FitzGerald, K., Seale, S., Kerins, C.A. and McElvaney, R. (2008). The critical incident technique: a useful tool for conducting qualitative research. Journal of Dental Education, 72(3), 299-304.

Flanagan, J. C. (1954). The critical incident technique. The Psychological Bulletin, 51(4), 327-358.

Flick, U. (2006). An introduction to qualitative research ( $3^{\text {rd }}$ ed.). London: Sage.

Glaser, B. G. (1998). Doing grounded theory: issues and discussions. Mill Valley: Sociology Press.

Group of Eight Australia. (n.d.). The importance of international education for Australia. URL: http://www.go8.edu.au/university-staff/agreements/theimportance-of-international-education-for-australia[accessed 4.9.11].

Head, A. \& Eisenberg, M. (2010). Truth to be told: How college students evaluate and use information in the digital age. Project Information Literacy Progress Report, 1 November 2010. Washington: The Information School. University of Washington. URL:

http://projectinfolit.org/pdfs/PIL_Fall2010_Survey_FullReport1.pdf [accessed 24.5.12]

Hughes, H. (2007), Critical incident technique. In S. Lipu, K. Williamson, \& Lloyd, A. Exploring methods in information literacy research (pp.49-66). Wagga Wagga: Centre for Information Studies. Charles Sturt University.

Hughes, H. (2009). International students using online information resources to learn. (Doctoral dissertation, QUT). URL: http://eprints.qut.edu.au/29348/ [accessed 11.1.10]. 
Hughes, H. (forthcoming). International students using online information resources to learn: complex experience and learning needs. Journal of Further and Higher Education. URL: http://www.tandfonline.com/doi/abs/10.1080/0309877X.2011.644778 [accessed 16.5.12].

Hughes, H., Bruce, C.S. and Edwards, S.L. (2007). Models for reflection and learning: A culturally inclusive response to the information literacy imbalance. In $\mathrm{S}$. Andretta (Ed.), Change and challenge: information literacy for the $21^{\text {st }}$ century (pp. 59-84). Adelaide: Auslib Press.

Kain, D. L. (1997). Critical incidents in teacher collaboration on interdisciplinary teams. Research in Middle Level Education Quarterly, 21(1), 1-9.

Kain, D. (2004). Owning significance: the critical incident technique in research. In K. deMarrais and S. D. Lapan (Eds.), Foundations for research: Methods of inquiry in education and the social sciences (pp. 69-85). Mahwah, NJ: Lawrence Erlbaum.

Kevat, P. and Shroff, R. (2010). International students in Australia: 2010 mid year market update. IDP Education. URL:

http://www.idp.com/pdf/22(a)_Australian\%20Market\%20Monitor\%20Report\%20 -\%202010\%20Mid\%20Year\%20NIDPR\%201210\%20(3).pdf [accessed 18.09.11].

Kvale, S. (1996). InterViews: an introduction to qualitative research interviewing. Thousand Oaks: Sage.

Le Mare, L and Sohbat, E. (2002). Canadian students' perceptions of teacher characteristics that support or inhibit help seeking. The Elementary School Journal, 102(3), 239-253.

Lincoln, Y. S. and Guba, E. G (1985). Naturalistic inquiry. Beverly Hills, CA: Sage.

Lorenzo, G., \& Dziuban, C. (2006). Ensuring the net generation is net savvy. ELI paper 2. Educause. Retrieved March 8, 2011, from http://www.educause.edu/ir/library/pdf/ELI3006.pdf [accessed 24.5.12]

Lupton, M. (2008). Information literacy and learning. Adelaide: Auslib Press.

MacIntosh-Murray, A. (2003). Information behaviour of health care providers for improving patient safety. (Doctoral dissertation, University of Toronto) [online]. URL: http://proquest.umi.com [Accessed 16.2.09].

Marginson, S. (2006). Dynamics of national and global competition in higher education. Higher Education, 52(1), pp.1-39.

Marton, F. \& Booth, S. (1997). Learning and Awareness. Hillsdale, NJ:

Lawrence Erlbaum.

Moon, J. A. (2004). A handbook of reflective and experiential learning: theory and practice. London: RoutledgeFalmer.

Patton, M. Q. (1990). Qualitative evaluation and research methods ( $2^{\text {nd }}$ ed.). Newbury Park: Sage. 
Radford, M. L. (2006). The critical incident technique and the qualitative evaluation of the Connecting Libraries and Schools Project. Library Trends, 55(1), 46-64.

Ronan, W.W. and Latham, G.P. (1974). The reliability and validity of the critical incident technique: a closer look. Studies in Personnel Psychology, 6(1), 53-64.

Schön, D. (1987). Educating the reflective practitioner. San Francisco, CA: Jossey-Bass.

Tenopir, C., King, D.W., Edwards, S. and Wu, L. (2009). Electronic journals and changes in scholarly article seeking and reading patterns. ASLIB Proceedings, 61(1), 5-32.

Trew, F. (2006). Serving different constituencies: International students. In P. Dale, M. Holland and M. Matthews (Eds.), Subject librarians: engaging with the learning and teaching environment. Aldershot: Ashgate (pp. 149-174).

Tripp, D. (1993). Critical incidents in teaching: developing professional judgement. London: Routledge.

Urquhart, C., Light, A., Thomas, R., Barker, A., Yeoman, A. Cooper, J., Armstrong, C., Fenton, R., Lonsdale, R. and Spink, S. (2003). Critical incident technique and explicitation interviewing in studies of information behavior. Library and Information Science Research, 25(1), 63-88.

Voss, R., Gruber, T. and Reppel, A. (2010). Which classroom service encounters make students happy or unhappy? Insights from an online CIT study. International Journal of Educational Management, 24(7), 615 - 636.

Woolsey, L.K. (1986). The critical incident technique: An innovative qualitative method of research. Canadian Journal of Counselling, 20(4), 242-254.

Zuber-Skerritt, O. (Ed.) (1996). New directions in action research. London:

Falmer.

\section{Acknowledgement}

Sincere appreciation to my QUT doctoral supervisors Professor Christine Bruce, Professor Susan Danby and Dr Michael Middleton, and critical friends Dr Mandy Lupton and Professor John Lidstone, for their continuing support and collaboration.

\section{Open access and copyright}

Library and Information Research is an open access journal. A freely available copy of this paper may be downloaded from the journal's website: http://www.cilipjournals.org.uk/lir 
Copyright and associated moral rights in works published in Library and Information Research are retained by the author(s) but this paper may be used freely, with proper attribution, in educational and other non-commercial settings. 